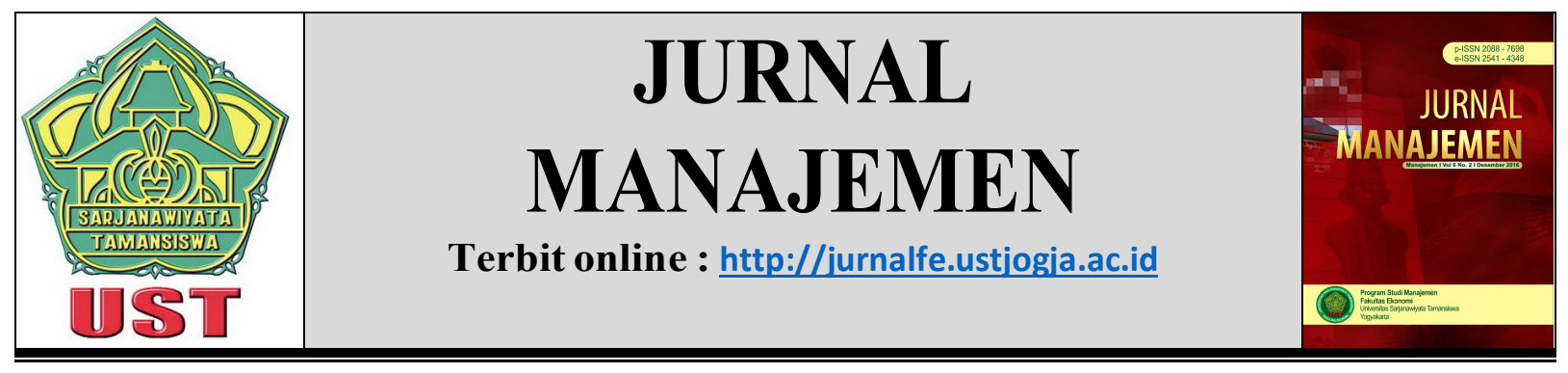

\title{
PENGARUH KUALITAS LAYANAN DAN ATMOSFER TOKO TERHADAP KEPUASAN KONSUMEN TOKO RITEL
}

\author{
Isnanda Zainur Rohman \\ STIE YKPN YOGYAKARTA
}

Korespondensi: isnanda.zainur@stieykpn.ac.id

\begin{tabular}{ll}
\hline Informasi Naskah & \multicolumn{1}{c}{ Abstrak } \\
\hline Diterima: & The purpose of this study was to determine the effect of service \\
25 April & quality (tangibles, reliability, responsiveness, assurance, and \\
Revisi: & empathy) and store atmosphere on cunsumer satisfaction of retail \\
$11 \mathrm{Mei}$ & stores. The respondents of this research were 200 consumers of a \\
Terbit: & retail store in Yogyakarta. Research respondents were determined \\
$16 \mathrm{Mei}$ & by using purposive sampling method. Data collection was done by \\
Kata Kunci: service & distributing questionnaires using 5-points Likert scale. Data \\
quality, store & analysis technique used was multiple linear regression. The test \\
atmosphere, consumer & results indicated that service quality and store atmosphere have an \\
satisfaction. & effect on consumer satisfaction. \\
\hline
\end{tabular}

\section{PENDAHULUAN}

Kepuasan konsumen adalah salah satu tujuan toko ritel, sehingga mereka dapat bertahan dalam jangka panjang (Kotler, 2017). Ciri dari kesuksesan toko ritel adalah ketika konsumen berkunjung kembali ke toko tersebut untuk kedua kalinya dan seterusnya. Kunjungan konsumen untuk kedua kalinya dan seterusnya dipengaruhi oleh kepuasan konsumen tersebut (Giese \& Cote, 2009; Nam, Ekinci, \& Whyatt, 2011).

Kepuasan konsumen adalah prioritas untuk pertumbuhan toko ritel (Jimanto, Yohanes, Kunto, \& Si, 2014). Kepuasan muncul dari persepsi dan harapan. Kepuasan konsumen akan terpenuhi ketika apa yang diberikan oleh toko ritel sesuai dengan apa yang diharapkan oleh konsumen. Kepuasan konsumen yang berkelanjutan adalah tujuan toko ritel sehingga toko ritel dapat bertahan (Johnson \& Distinguished, 2013).

Kepuasan konsumen merupakan perasaan atau penilaian emosional konsumen terhadap penggunaan produk dan layanan. Kepuasan konsumen adalah sumber utama pendapatan dan kunci utama untuk memenangkan kompetisi (Giese \& Cote, 2009). Ketika konsumen puas, ia enggan untuk berpindah ke toko lain. Konsumen yang merasa puas akan menjadi loyal dan memberikan pemasukan yang bekelanjutan untuk toko ritel. 
Terkait dengan kepuasan konsumen, kualitas layanan merupakan hal penting yang dapat mempengaruhi kepuasan konsumen (Schiffman \& Kanuk, 2007). Kualitas layanan membentuk hubungan psikologis yang kuat antara konsumen dan toko ritel. Sebuah toko ritel dapat berhasil dalam memberikan layanan ketika layanan tersebut memenuhi harapan pelanggan. Namun dalam kenyataannya, belum semua toko ritel memperhatikan hal itu. Terdapat banyak karyawan yang sibuk berbicara dengan karyawan lain dan mereka lupa bahwa kebutuhan konsumen perlu dipehatikan (Jimanto et al., 2014).

Hal lain yang dapat mempengaruhi kepuasan konsumen ketika mengunjungi toko ritel adalah atmosfer toko. Atmosfer toko adalah suasana yang diciptakan untuk memberikan nilai tambah dan memberi kesan positif di benak konsumen (Hussain \& Ali, 2015). Atmosfer toko juga dapat mempengaruhi psikologis konsumen, sehingga mereka merasa nyaman berbelanja di toko (Han Shen \& Tsuifang, 2011). Atmosfer toko adalah salah satu hal yang diperhatikan pelanggan ketika berkunjung ke toko. Suasana yang menyenangkan akan mempengaruhi tingkat kepuasan konsumen.

Terdapat dua rumusan masalah dalam penelitian ini. Pertama, apakah kualitas layanan (tangibles, reliability, responsiveness, assurance, and empathy) berpengaruh terhadap kepuasan konsumen toko ritel. Kedua, apakah atmosfer toko berpengaruh terhadap kepuasan konsumen toko ritel.

Manfaat dari penelitian ini adalah penelitian ini diharapkan dapat menambah khasanah penelitian dalam bidang ilmu manajemen toko ritel, khususnya terkait aspek kualitas layanan, atmosfer toko, dan kepuasan konsumen toko ritel. Sedangkan kegunaan praktis dari penelitian ini adalah hasil penelitian ini diharapkan dapat berguna sebagai bahan pertimbangan bagi manajemen toko ritel dalam merumuskan kebijakan.

\section{KAJIAN PUSTAKA DAN HIPOTESIS Pengertian Toko Ritel}

Kegiatan ritel merupakan bagian penting dalam proses rantai konsumsi. Kegiatan ini disebut juga penjualan eceran karena aktivitas bisnisnya adalah menjual produk kepada konsumen akhir (Goworek \& McGoldrick, 2015). Kegiatan ritel adalah kegiatan usaha menjual barang atau jasa kepada perorangan untuk keperluan diri sendiri, keluarga atau rumah tangga (Akehurst \& Alexander, 2013). Terdapat pandangan bahwa kegiatan ritel adalah hanya melakukan penjualan produk di toko, namun sebenarnya jasa yang ditawarkan oleh dokter gigi juga dapat disebut kegiatan ritel. Kegiatan ritel adalah serangkaian kegiatan usaha yang memberikan nilai tambah pada produk dan jasa yang dijual kepada pelanggan untuk penggunaan pribadi atau keluarga (Elsner, 2001).

Toko ritel adalah suatu usaha yang kegiatannya menyangkut penjualan barang secara langsung kepada konsumen untuk penggunaan pribadi (Utomo, 2010). Toko ini melakukan penjualan langsung kepada konsumen akhir. Dengan demikian, toko ritel menjadi distributor akhir yang menghubungkan produsen dengan konsumen (Pantano, 2014). Penjualan eceran atau ritel adalah semua kegiatan yang melibatkan penjualan produk secara langsung kepada konsumen akhir untuk penggunaan pribadi, bukan untuk diperdagangkan lagi. Dalam penelitian ini, toko ritel didefinisikan sebagai toko yang menjual barang-barang kepada konsumen akhir.

\section{Kepuasan Konsumen}

Kepuasan adalah perasaaan seseorang yang muncul setelah membandingkan antara persepsi terhadap kenyataan (Schiffman \& Kanuk, 2007). Kepuasan konsumen adalah respon 
atau reaksi terhadap kesesuaian antara tingkat kepentingan sebelumnya dan kinerja yang dirasakan setelah penggunaan atau pemakaian. Kepuasan konsumen sangat bergantung kepada persepsi dan harapan konsumen (Wang, 2012).

Adapun menurut Schiffman \& Kanuk (2007) faktor-faktor yang mempengaruhi persepsi dan harapan konsumen adalah sebagai berikut:

1. Kebutuhan dan keinginan yang berkaitan dengan hal-hal yang dirasakan konsumen ketika sedang mencoba melakukan transaksi.

2. Pengalaman masa lalu ketika mengkonsumsi produk dari perusahaan maupun pesaingpesaingnya.

3. Pengalaman dari teman-teman.

Kepuasan adalah evaluasi setelah konsumsi untuk memilih beberapa alternatif dalam rangka memenuhi harapan (Giese \& Cote, 2009). Kepuasan tercapai ketika kualitas memenuhi atau melebihi harapan, keinginan dan kebutuhan konsumen. Sebaliknya, jika kualitas tidak memenuhi atau melebihi harapan, keinginan dan kebutuhan konsumen, maka kepuasan tidak tercapai. Konsumen yang tidak puas terhadap barang atau jasa yang dikonsumsinya akan mencari perusahaan lain yang mampu menyediakan kebutuhannya (Williams, 2014).

Kepuasan konsumen telah menjadi konsep sentral dalam teori dan praktek pemasaran, serta merupakan faktor yang esensial bagi kegiatan bisnis (Rytel, 2010). Kepuasan konsumen toko ritel merupakan tingkat perasaan seseorang setelah membandingkan perasaan yang ia rasakan setelah berkunjung ke toko yang dibandingkan dengan harapannya (Dai, Luo, Liao, \& Cao, 2015). Dari berbagai pendapat di atas dapat disimpulkan definisi kepuasan konsumen toko ritel adalah tingkat perasaan seseorang setelah membandingkan kenyataan saat berkunjung ke toko ritel dengan harapannya

\section{Kualitas Layanan}

Kualitas pelayanan mengacu pada kualitas yang diharapkan dan dirasakan konsumen (Yarimoglu, 2014). Terdapat banyak perusahaan yang memprioritaskan kualitas layanan untuk memuaskan konsumennya. Dimensi kualitas layanan dalam model SERVQUAL (service quality) didasarkan pada skala multi item yang dirancang untuk mengukur harapan dan persepsi konsumen (Sivakumar, Li, \& Dong, 2014).

Pada awalnya terdapat sepuluh dimensi pokok dengan 22 variabel yang berkaitan dengan pelayanan dan kemudian dianalisis dengan memakai analisis faktor. Ternyata dapat dikemukakan beberapa kriteria yang digunakan dalam menilai mutu pelayanan. Kriteria tersebut meliputi 10 dimensi potensial yang saling melengkapi yaitu tangibles, reliability, responsiveness, communication, credibility, security, competence, courtesy, understanding dan access. Kemudian pada penelitian selanjutnya Parasuraman, Zeithaml, \& Berry (1988) menyempurnakan dimensi tersebut dan diolah lagi sehingga akhirnya disederhanakan menjadi 5 dimensi, yaitu:

1. Bukti langsung (tangibles); meliputi fasilitas fisik, perlengkapan, pegawai, sarana dan prasarana.

2. Keandalan (reliability); yakni kemampuan memberikan pelayanan yang dijanjikan dengan segera, akurat, dan dapat diandalkan.

3. Daya tanggap (responsiveness); yaitu keinginan para pegawai untuk membantu para pelanggan dan memberikan pelayanan dengan tanggap .

4. Jaminan (assurance); mencakup pengetahuan, kemampuan, kesopanan, dan sifat dapat dipercaya yang dimiliki para staf. 
5. Empati (empathy); meliputi kemudahan dalam melakukan hubungan, komunikasi yang baik, perhatian pribadi, dan memahami kebutuhan para pelanggan.

\section{Atmosfer Toko}

Atmosfer toko merupakan suasana yang dirasakan konsumen saat berada di lingkungan toko (Zielke \& Schielke, 2011). Atmosfer toko dapat didefinisikan sebagai perubahan terhadap perancangan lingkungan pembelian yang menghasilkan efek emosional khusus yang dapat membuat konsumen merasa nyaman (Hussain \& Ali, 2015). Suatu toko perlu membentuk suasana terencana yang sesuai dengan pasar sasarannya dan dapat menarik konsumen untuk membeli di toko tersebut.

Atmosfer toko merupakan kesan keseluruhan yang disampaikan oleh tata letak fisik toko, dekorasi, dan lingkungan sekitarnya (Nofiawaty, 2014). Atmosfer toko merupakan suatu kombinasi atau gabungan dari pesan secara fisik yang telah direncanakan (Cho \& Lee, 2017). Atmosfer toko merupakan usaha merancang lingkungan pembeli untuk menghasilkan pengaruh emosional khusus kepada pembeli yang kemungkinan meningkatkan pembeliannya.

Atmosfer toko dipercaya dapat mempengaruhi konsumen untuk menghabiskan uang di luar tingkat yang direncanakan di sebuah toko (Jiang \& Liu, 2014). Atmosfer toko mempengaruhi keadaan emosional konsumen, yang kemudian mendorong untuk meningkatkan atau mengurangi belanja. Keadaan emosional terdiri dari dua perasaan yang dominan yaitu kesenangan dan gairah (Han Shen \& Tsuifang, 2011).

Ketika suasana konsumen bergairah secara positif, maka konsumen cenderung menghabiskan lebih banyak waktu di toko (Helmefalk \& Hultén, 2017). Situasi ini dapat menyebabkan pembelian meningkat. Sebaliknya, jika lingkungan tidak menyenangkan dan membuat emosi konsumen menjadi negatif, maka pembeli akan menghabiskan lebih sedikit waktu di toko dan melakukan sedikit pembelian.

Berdasarkan beberapa definisi tersebut di atas, maka dapat ditarik kesimpulan bahwa atmosfer toko merupakan seluruh efek estetika dan emosional yang diciptakan melalui ciri-ciri fisik dari toko yang semuanya berhubungan dengan panca indera dari konsumen dan dapat mempengaruhi perasaan konsumen.

\section{METODE PENELITIAN}

Tipe penelitian ini adalah penelitian kuantitatif. Dalam penelitian kuantitatif, terdapat data yang berupa angka-angka yang diolah dengan statistika sehingga menghasilkan kesimpulan (Sekaran \& Bougie, 2014). Dalam penelitian ini, terdapat 6 variabel yang diukur menggunakan kuesioner yang memiliki skala Likert 5 poin.

Data dalam penelitian ini adalah data primer. Data primer adalah data yang didapatkan melalui jawaban langsung dari responden (Sekaran \& Bougie, 2014). Peneliti mendapatkan data primer dari hasil jawaban kuesioner yang diisi oleh reponden yang merupakan konsumen toko ritel.

Berdasarkan kajian teori dan hasil penelitian sebelumnya, model penelitian dalam penelitian ini adalah sebagai berikut: 


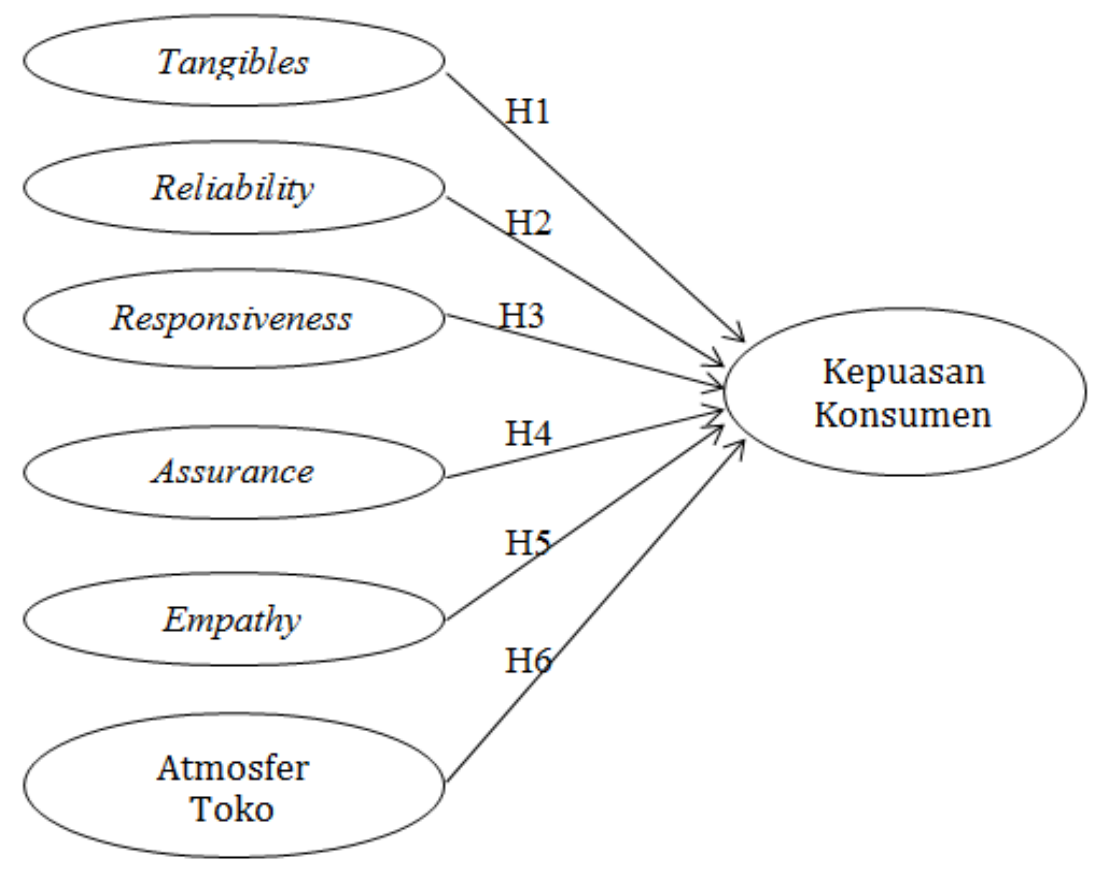

Gambar 1.1 Model Penelitian

Terdapat 28 indikator yang mewakili 7 variabel: tangibles, reliability, responsiveness, assurance, empathy, atmosfer toko, dan kepuasan konsumen. Setiap pernyataan dalam kuesioner memiliki skor nilai dari 1 sampai 5 poin dengan penjelasan sebagai berikut:

5 = Jawaban SS (sangat setuju)

$4=$ Jawaban S (setuju)

3 = Jawaban N (netral)

2 = Jawaban TS (tidak setuju)

$1=$ Jawaban STS (sangat tidak setuju)

Tinggi rendahnya validitas instrumen menunjukkan sejauh mana data yang terkumpul tidak meyimpang dari gambaran tentang variabel yang dimaksud. Sebuah pernyataan dalam kuesioner dikatakan valid jika mampu mengukur apa yang seharusnya diukur ditunjukkan dengan nilai loading factor $\geq 0,5$ (Hair, Black, Babin, \& Anderson, 2010).

Uji reliabilitas bertujuan untuk mencari tahu sejauh mana kosistensi alat ukur yang digunakan, sehingga bila alat ukur tesebut digunakan kembali untuk meneliti obyek yang sama dan dengan teknik yang sama pula walaupun waktunya berbeda, maka hasil yang akan diperoleh adalah sama. Uji reabilitas mampu menunjukan sejauh mana instrumen dapat dipercaya. Suatu instrumen dikatakan reliabel bila nilai cronbach alpha $\geq 0,6$ (Hair et al., 2010).

Uji asumsi klasik digunakan untuk memperoleh model analisis yang tepat. Model regresi yang tepat harus menghindari kemungkinan terjadinya penyimpangan asumsi klasik (Ghozali, 2012). Uji asumsi klasik yang dilakukan terhadap data pada penelitian ini adalah uji normalitas, heteroskedastisitas dan multikolinearitas.

Uji normalitas digunakan untuk mengetahui apakah nilai residual yang telah distandarisasi pada model regresi terdistribusi secara normal. Data disebut terdistribusi normal jika nilai residual mendekati nilai rata-ratanya (Ghozali, 2012).

Uji heteroskedastisitas digunakan untuk mengetahui apakah model regresi yang 
dibentuk sudah bersifat homoskedastisitas yang semua varian dari residual satu pengamatan ke pengamatan lain harus mempunyai nilai yang sama. Bila ditemukan ketidaksesamaan atau heteroskedastisitas maka dapat menyebabkan uji signifikansi statistik tidak valid (Ghozali, 2012).

Uji multikolinearitas digunakan untuk melihat pembentukan korelasi yang tinggi atau sempurna diantara variabel bebas. Jika terjadi korelasi yang tinggi, dapat dikatakan terjadi murtikolinearritas. Pada model regresi yang tepat, tidak boleh terjadi multikolinearitas. Multikolinearitas dapat dilihat dari nilai variance inflation factor (VIF). Jika nilai VIF $<10$, maka data bebas dari gejala multikolinieritas (Ghozali, 2012).

Untuk menguji hipotesis, data dalam penelitian ini dianalisis menggunakan regresi linier berganda, untuk mengetahui ketergantungan suatu variabel terikat dengan variabel bebas. Dalam analisis, peneliti menggunakan program komputer Statistical Package of Social Science (SPSS) version 23.0 for Windows.

\section{HASIL DAN PEMBAHASAN}

Sebanyak 200 responden terlibat dalam penelitian ini. Responden tersebut dapat dikategorikan ke dalam beberapa jenis berdasarkan demografi seperti jender, umur, dan tingkat pendidikan terakhir. Berikut adalah tabel 1 yang menunjukkan persentase dan jumlah responden yang dibedakan oleh beberapa jenis karakteristik demografi.

Tabel 1

Karakteristik Responden

\begin{tabular}{|c|c|c|c|c|}
\hline No. & Jenis & Ketegori & Jumlah & Persentase \\
\hline \multirow[t]{2}{*}{1} & Jender & Laki - laki & 90 & $28 \%$ \\
\hline & & Perempuan & 110 & $72 \%$ \\
\hline & Umur & $21-30$ tahun & 40 & $20 \%$ \\
\hline & & $31-40$ tahun & 70 & $35 \%$ \\
\hline & & $41-50$ tahun & 88 & $44 \%$ \\
\hline & & $51-60$ tahun & 12 & $6 \%$ \\
\hline \multirow[t]{4}{*}{3} & Pendidikan terakhir & SMP & 10 & $5 \%$ \\
\hline & & SMA & 90 & $45 \%$ \\
\hline & & $\mathrm{S} 1$ & 76 & $38 \%$ \\
\hline & & $\mathrm{S} 2$ & 24 & $12 \%$ \\
\hline
\end{tabular}

Tabel 2 menunjukkan nilai dari masing-masing indikator variabel memiliki nilai loading factor lebih besar dari 0,5. Analisis faktor dinyatakan valid jika memenuhi syarat loading factor lebih besar dari 0,5 (Hair et al., 2010).

Tabel 2

Hasil Uji Validitas

\begin{tabular}{|ccccc|}
\hline No. & Variabel & Indikator & Loading Factor & Keterangan \\
\hline 1. & Kepuasan Konsumen $(\mathrm{Y})$ & $\mathrm{Y} 1$ & 0,915 & Valid \\
& & $\mathrm{Y} 2$ & 0,826 & Valid \\
& & $\mathrm{Y} 3$ & 0,866 & Valid \\
& & $\mathrm{Y} 4$ & 0,812 & Valid \\
\hline 2. & Tangibles $(\mathrm{X} 1)$ & $\mathrm{X} 1.1$ & 0,967 & Valid \\
\hline
\end{tabular}




\begin{tabular}{|lllll|}
\hline & & $\mathrm{X} 1.2$ & 0,878 & Valid \\
& & $\mathrm{X} 1.3$ & 0,865 & Valid \\
\hline 3. & Reliability (X2) & $\mathrm{X} 1.4$ & 0,901 & Valid \\
& & $\mathrm{X} 2.1$ & 0,934 & Valid \\
& & $\mathrm{X} 2.2$ & 0,902 & Valid \\
& & $\mathrm{X} 2.3$ & 0,787 & Valid \\
\hline 4. & Responsiveness $(\mathrm{X} 3)$ & $\mathrm{X} 2.4$ & 0,799 & Valid \\
& & $\mathrm{X} 3.1$ & 0,917 & Valid \\
& & $\mathrm{X} 3.2$ & 0,901 & Valid \\
& & $\mathrm{X} 3.3$ & 0,704 & Valid \\
\hline 5. & Assurance (X4) & $\mathrm{X} 3.4$ & 0,799 & Valid \\
& & $\mathrm{X} 4.1$ & 0,729 & Valid \\
& & $\mathrm{X} 4.2$ & 0,888 & Valid \\
& & $\mathrm{X} 4.3$ & 0,762 & Valid \\
\hline 6. & Empathy (X5) & $\mathrm{X} 4.4$ & 0,824 & Valid \\
& & $\mathrm{X} 5.1$ & 0,754 & Valid \\
& & $\mathrm{X} 5.2$ & 0,901 & Valid \\
& & $\mathrm{X} 5.3$ & 0,893 & Valid \\
\hline 7. & Atmosfer Toko & $\mathrm{X} 5.4$ & 0,877 & Valid \\
\hline & & $\mathrm{X} 6.1$ & 0,743 & Valid \\
& & $\mathrm{X} 6.2$ & 0,721 & Valid \\
& & $\mathrm{X} 6.3$ & 0,878 & Valid \\
& & $\mathrm{X} 6.4$ & 0,865 & Valid \\
\hline
\end{tabular}

Tabel 3 menunjukkan masing-masing nilai Cronbach's Alpha pada tiap variabel lebih besar dari 0,60 (Cronbach's Alpha >0,60). Hal tersebut menunjukkan bahwa semua instrumen reliabel, sehingga dapat digunakan untuk melakukan penelitian (Hair et al., 2010).

Tabel 3

Hasil Uji Realibilitas

\begin{tabular}{|clcc|}
\hline No. & \multicolumn{1}{c}{ Variabel } & Cronbach's Alpha & Keterangan \\
\hline 1. & Kepuasan Konsumen $(\mathrm{Y})$ & 0,867 & Reliable \\
\hline 2. & Tangibles $(\mathrm{X} 1)$ & 0,708 & Reliable \\
\hline 3. & Reliability $(\mathrm{X} 2)$ & 0,791 & Reliable \\
\hline 4. & Responsiveness $(\mathrm{X} 3)$ & 0,877 & Reliable \\
\hline 5. & Assurance $(\mathrm{X} 4)$ & 0,878 & Reliable \\
\hline 6. & Empathy $(\mathrm{X} 5)$ & 0,796 & Reliable \\
\hline 7. & Atmosfer Toko $(\mathrm{X} 6)$ & 0,890 & Reliable \\
\hline
\end{tabular}

Sebelum dilakukan uji regresi linier berganda, terlebih dahulu dilakukan uji asumsi klasik. Hasil dari uji asumsi klasik dalam penelitian ini menunjukkan bahwa data terdistribusi normal, tidak terjadi multikolinieritas, dan tidak terdapat gejala heterokedastisitas. Setelah hasil uji asumsi klasik terpenuhi, langkah selanjutnya adalah uji regresi berganda yang hasilnya ditunjukkan di tabel 4 berikut: 
Tabel 4

Hasil Uji Regresi

\begin{tabular}{|lccl|}
\hline \multicolumn{1}{|c}{ Hipotesis } & $\begin{array}{c}\text { Standardized } \\
\text { Regression } \\
\text { Weights }\end{array}$ & Probability & Keterangan \\
\hline $\begin{array}{l}\text { H1: Tangibles berpengaruh terhadap } \\
\text { kepuasan konsumen }\end{array}$ & 0,202 & $\mathrm{p}<0,05$ & $\begin{array}{l}\text { Hipotesis } \\
\text { didukung }\end{array}$ \\
\hline $\begin{array}{l}\text { H2: Reliability berpengaruh terhadap } \\
\text { kepuasan konsumen }\end{array}$ & 0,234 & $\mathrm{p}<0,05$ & $\begin{array}{l}\text { Hipotesis } \\
\text { didukung }\end{array}$ \\
\hline $\begin{array}{l}\text { H3: Responsiveness berpengaruh } \\
\text { terhadap kepuasan konsumen }\end{array}$ & 0,426 & $\mathrm{p}<0,05$ & $\begin{array}{l}\text { Hipotesis } \\
\text { didukung }\end{array}$ \\
\hline $\begin{array}{l}\text { H4: Assurance berpengaruh terhadap } \\
\text { kepuasan konsumen }\end{array}$ & 0,402 & $\mathrm{p}<0,05$ & $\begin{array}{l}\text { Hipotesis } \\
\text { didukung }\end{array}$ \\
\hline $\begin{array}{l}\text { H5: Empathy berpengaruh terhadap } \\
\text { kepuasan konsumen }\end{array}$ & 0,442 & $\mathrm{p}<0,05$ & $\begin{array}{l}\text { Hipotesis } \\
\text { didukung }\end{array}$ \\
\hline $\begin{array}{l}\text { H6: Atmosfer toko berpengaruh } \\
\text { terhadap kepuasan konsumen }\end{array}$ & 0,545 & $\mathrm{p}<0,05$ & $\begin{array}{l}\text { Hipotesis } \\
\text { didukung }\end{array}$ \\
\hline
\end{tabular}

Hasil analisis yang pertama yaitu seluruh dimensi kualitas layanan (tangibles, reliability, responsiveness, assurance, and empathy) terbukti berpengaruh terhadap kepuasan konsumen ditunjukkan dengan nilai $p<0,05$. Hasil ini mendukung hasil penelitian Hersanti \& Ratnawati (2012) dan Wijaya (2017) yang menyatakan bahwa kualitas layanan merupakan salah satu faktor yang dapat memberikan pengaruh terhadap kepuasan konsumen.

Hasil analisis yang kedua yaitu atmosfer toko berpengaruh terhadap kepuasan konsumen ditunjukkan dengan nilai $p<0,05$. Hasil penelitian ini sesuai dengan hasil penelitian Cho \& Lee (2017) dan Helmefalk \& Hultén (2017) yang menunjukkan bahwa atmosfer toko berpengaruh terhadap kepuasan konsumen.

\section{PENUTUP}

Tujuan dari penelitian ini adalah untuk mengetahui apakah kualitas layanan (tangibles, reliability, responsiveness, assurance, and empathy) dan atmosfer toko berpengaruh terhadap kepuasan konsumen toko ritel. Berdasarkan hasil dan pembahasan pada bagian sebelumnya, maka dapat disimpulkan bahwa semua dimensi dari kualitas layanan (tangibles, reliability, responsiveness, assurance, and empathy) dan atmosfer toko terbukti berpengaruh terhadap kepuasan konsumen toko ritel.

Berdasarkan kesimpulan di atas, saran yang dapat disampaikan oleh peneliti adalah sebaiknya manajer toko ritel memperhatikan kualitas layanan (tangibles, reliability, responsiveness, assurance, and empathy) dan atmosfer toko, sehingga diharapkan dapat meningkatkan kepuasan konsumen dan toko ritel dapat semakin berkembang.

\section{REFERENSI}

Akehurst, G., \& Alexander, N. (2013). Retail marketing. Retail Marketing. https://doi.org/10.4324/9780203044124 
Chih-Hung Wang, M. (2012). Determinants and consequences of consumer satisfaction with self-service technology in a retail setting. Managing Service Quality: An International Journal, 22(2), 128-144. https://doi.org/10.1108/09604521211218945

Cho, J. Y., \& Lee, E. J. (2017). Impact of Interior Colors in Retail Store Atmosphere on Consumers' Perceived Store Luxury, Emotions, and Preference. Clothing and Textiles Research Journal, 35(1), 33-48. https://doi.org/10.1177/0887302X16675052

Dai, H., Luo, X., Liao, Q., \& Cao, M. (2015). Explaining consumer satisfaction of services: The role of innovativeness and emotion in an electronic mediated environment. Decision Support Systems, 70, 97-106. https://doi.org/10.1016/j.dss.2014.12.003

Elsner, S. (2001). Retail Internationalization. British Journal of Management (Vol. 12). https://doi.org/10.1007/978-3-658-01096-6

Ghozali, I. (2012). Statistik Non-Parametrik: Teori dan Aplikasi dengan Program SPSS. Universitas Diponegoro. Semarang.

Giese, J. L., \& Cote, J. a. (2009). Defining Consumer Satisfaction. Academy of Marketing Science Review, 1(3), 272-8. https://doi.org/10.1111/j.1365-2850.2008.01371.x

Goworek, H., \& McGoldrick, P. (2015). Retail Marketing Management. Management.

Hair, J. F., Black, W. C., Babin, B. J., \& Anderson, R. E. (2010). Multivariate Data Analysis. Vectors. https://doi.org/10.1016/j.ijpharm.2011.02.019

Han Shen, C., \& Tsuifang, H. (2011). The effect of atmosphere on customer perceptions and customer behavior responses in chain store supermarkets. African Journal of Business Management, 5(24), 10054-10066. https://doi.org/10.5897/AJBM10.608

Helmefalk, M., \& Hultén, B. (2017). Multi-sensory congruent cues in designing retail store atmosphere: Effects on shoppers' emotions and purchase behavior. Journal of Retailing and Consumer Services, 38, 1-11. https://doi.org/10.1016/j.jretconser.2017.04.007

Hersanti, N. J., \& Ratnawati, K. (2012). Pengaruh Atmosfer Terhadap Kepuasan dan Niatan Perilaku Konsumen di Toko ” Oen ”, Kota Malang. Ekonomi Dan Bisnis, 10(4), 772780.

Hussain, R., \& Ali, M. (2015). Effect of Store Atmosphere on Consumer Purchase Intention. International Journal of Marketing Studies, 7(2). https://doi.org/10.5539/ijms.v7n2p35

Jiang, P., \& Liu, X. (2014). The Influence of Store Atmosphere on Shoppers' Impulse Purchasing Behavior. Thesis, 5(8), 90. https://doi.org/10.5901/mjss.2014.v5n8p229

Jimanto, R. B., Yohanes, D., Kunto, S., \& Si, S. (2014). Pengaruh Service Quality Terhadap Loyalitas Pelanggan Dengan Customer Satisfaction Sebagai Variabel Intervening Pada Ritel Bioskop the Premiere Surabaya. Jurnal Manajemen Pemasaran Petra, 2(1), 1-7.

Johnson, S. C., \& Distinguished, S. (2013). Retail Industry Snapshot. Retail Snapshot, 15. Kotler, P. (2017). Philip Kotler: some of my adventures in marketing. Journal of Historical Research in Marketing, 9(2), 203-208. https://doi.org/10.1108/JHRM-11-2016-0027

Nam, J., Ekinci, Y., \& Whyatt, G. (2011). Brand equity, brand loyalty and consumer satisfaction. Annals of Tourism Research, 38(3), 1009-1030. https://doi.org/10.1016/j.annals.2011.01.015

Nofiawaty, beli yuliandi. (2014). Pengaruh Store Atmosphere Terhadap Keputusan Pembelian Konsumen. Journal of Menegement and Bussines.

Pantano, E. (2014). Innovation drivers in retail industry. International Journal of Information Management. https://doi.org/10.1016/j.ijinfomgt.2014.03.002

Parasuraman, A., Zeithaml, A. V., \& Berry, L. L. (1988). SERVQUAL: A multiple-item scale for measuring consumer perceptions of service quality. Journal of Retailing, Volume 
64(1), 12-40.

Rytel, T. (2010). Emotional marketing concept: the new marketing shift in the postmodern era. Verslas: Teorija Ir Praktika, 11(1), 30-38. https://doi.org/10.3846/btp.2010.04

Schiffman, L., \& Kanuk, L. L. (2007). Consumer Behavior. New Jersey.

Sekaran, U., \& Bougie, R. (2014). Research methods for business. In Research methods for business (p. 436).

Sivakumar, K., Li, M., \& Dong, B. (2014). Service Quality: The Impact of Frequency, Timing, Proximity, and Sequence of Failures and Delights. Journal of Marketing, 78(1), 41-58. https://doi.org/10.1509/jm.12.0527

Utomo, T. J. (2010). LINGKUNGAN BISNIS DAN PERSAINGAN BISNIS RITEL. Fokus Ekonomi. Retrieved from http://ejournal.stiepena.ac.id/index.php/fokus/article/view/79

Wijaya, C. V. (2017). Pengaruh Harga, Kualitas Pelayanan, dan Kualitas Produk terhadap Kepuasan Konsumen Depot Madiun Masakan Khas Bu Rudy. AGORA, 5(1).

Williams, P. (2014). Emotions and Consumer Behavior. Journal of Consumer Research, 40(5), viii-xi. https://doi.org/10.1086/674429

Yarimoglu, E. K. (2014). A Review on Dimensions of Service Quality Models. Journal of Marketing Management, 2(2), 79-93.

Zielke, S., \& Schielke, T. (2011). How Store Lighting Influences Store Atmosphere, Price and Quality Perceptions and Shopping Intention. European Marketing Academy 40th Conference, 1-7. 